\title{
Contents of the Forthcoming Issue
}

\author{
(Tentative)
}

Some Aspects of Civil Procedure and Practice at the Trial Level During Ch'ing Times in Tanshui and Hsinchu from $1789-1895$

David C. Buxbaum

Financial Expertise, Examinations, and the Formulation of Economic Policy in Northern Sung China

Robert M. Hartwell

The Problem of Recruitment for the Indian Civil Service During the Late Nineteenth Century Bradford Spangenberg

Continuities of Social Mobility in Traditional and Modern Society in India: Two CaseStudies of Caste Mobility in Bengal Hitesranjan Sanyal

On the Origins of Gandhi's Political Methodology: The Heritage of Kathiawad and Gujarat Howard Spodek

A Quiet Transformation in Tokugawa Economic History Susan B. Hanley and Kozo Yamamura 